\title{
The effectiveness of metal on metal hip resurfacing: a systematic review of the available evidence published before 2002 Laura Wyness*1, Luke Vale ${ }^{2,3}$, Kirsty McCormack², Adrian Grant ${ }^{2}$ and Miriam Brazzelli²
}

Address: ${ }^{1}$ Department of Public Health, University of Aberdeen, Aberdeen, UK, ${ }^{2}$ Health Services Research Unit, University of Aberdeen, Aberdeen, UK and ${ }^{3}$ Health Economics Research Unit, University of Aberdeen, Aberdeen, UK

Email: Laura Wyness* - l.wyness@abdn.ac.uk; Luke Vale - l.vale@abdn.ac.uk; Kirsty McCormack - k.mccormack@abdn.ac.uk; Adrian Grant - a.grant@abdn.ac.uk; Miriam Brazzelli - m.brazzelli@abdn.ac.uk

* Corresponding author

Published: 27 December 2004

BMC Health Services Research 2004, 4:39 doi:10.1186/1472-6963-4-39

This article is available from: http://www.biomedcentral.com/l472-6963/4/39

(C) 2004 Wyness et al; licensee BioMed Central Ltd.

This is an Open Access article distributed under the terms of the Creative Commons Attribution License (http://creativecommons.org/licenses/by/2.0), which permits unrestricted use, distribution, and reproduction in any medium, provided the original work is properly cited.
Received: 30 January 2004

Accepted: 27 December 2004

\begin{abstract}
Background: Conventional total hip replacement (THR) may be felt to carry too high a risk of failure over a patient's lifetime, especially in young people. There is increasing interest in metal on metal hip resurfacing arthroplasty (MoM) as this offers a bone-conserving option for treating those patients who are not considered eligible for THR. We aim to evaluate the effectiveness of MoM for treatment of hip disease, and compare it with alternative treatments for hip disease offered within the UK.
\end{abstract}

Methods: A systematic review was carried out to identify the relevant literature on MoM published before 2002. As watchful waiting and total hip replacement are alternative methods commonly used to alleviate the symptoms of degenerative joint disease of the hip, we compared MoM with these.

Results: The data on the effectiveness of MoM are scarce, as it is a relatively new technique and at present only short-term results are available.

Conclusion: It is not possible to make any firm conclusions about the effectiveness of MoM based on these early results. While the short-term results are promising, it is unclear if such results would be replicated in more rigorous studies, and what the long-term performance might be. Further research is needed which ideally should involve long-term randomised comparisons of MoM with alternative approaches to the clinical management of hip disease.

\section{Background}

The treatment of younger people with disease of the hip joint presents a difficult clinical problem. Conventional total hip replacement (THR) may be felt to carry too high a risk of failure over a patient's lifetime. Overall, longterm results of THR in younger patients with a variety of underlying conditions indicate that $25-30 \%$ may require revision by 15 years [1], compared with less than five percent at ten years for older patients, and less than ten percent at ten or more years for all patients [2]. Specific subgroups of young active patients, such as those with osteoarthritis, may experience a revision rate of 50\% [3]. In 1999/00 in the NHS in England 18\% $(8,389)$ of THRs were performed on people aged between 15 and 59, 46\% 
$(21,440)$ in people aged 60 to 74 , and $36 \%(27,965)$ in people aged 75 and over [4]. Data on the number of revisions performed was not so readily available. A previous report suggested that out of approximately 2700 THRs per year, $2100(78 \%)$ are primary THRs and $600(22 \%)$ are revisions [5]. More recent data on revisions of THRs as a percentage of the total number of THR procedures suggest that in 1998/99 over ten percent of all THRs were carried out as revisions [6]. Due to concerns about the risks of revision, people who are expected to outlive a primary THR are often managed with non-surgical interventions, such medication to alleviate pain and to delay or prevent the need for surgery; collectively these interventions have been referred to as 'watchful waiting' (WW). People are typically referred for surgery only when their symptoms (e.g. pain, loss of physical function) become unmanageable by non-surgical means. Figures for the number of people who have their symptoms managed by pain control and other non-surgical interventions (such as the use of transcutaneous electrical nerve therapy and strengthening exercises) within England and Wales are difficult to determine. Evidence from a population survey suggest that 15.2 people per 1000 aged 35 to 85 years had hip disease severe enough for surgery. This equates to approximately 760,000 people within England and Wales [7].

Metal on metal hip resurfacing arthroplasty (MoM) offers a bone-conserving option for treating those patients who are not considered eligible for THR. MoM may also represent a more attractive alternative to other procedures such as osteotomy, bone fusion and arthroscopy, which have previously been used or been advocated as means of delaying or preventing the need for a THR. MoM involves the removal and replacement of the surface of the femoral head with a hollow metal hemisphere, which fits into a metal acetabular cup. This technique conserves femoral bone (although it is not conservative on the acetabular side), maintains normal femoral loading and stresses, and may not therefore compromise future total hip replacements. Data on the use of MoM within the NHS in England and Wales could not be obtained in this review. Never the less, because of increasing interest in MoM, we conducted a systematic review of the evidence of effectiveness aiming to compare it with THR and watchful waiting.

\section{Methods \\ Search strategy}

Initial searches failed to identify any randomised or comparative observational studies comparing MoM with any of the chosen alternatives. A structured search was conducted to identify evidence relating to the clinical effectiveness and cost-effectiveness of MoM for treatment of hip disease. The search strategy comprised of: (1) A free text search to identify any potentially relevant papers evaluating MoM (free text search terms were used because of the anticipated scarcity of published literature); and (2) A search for RCTs and systematic reviews of RCTs for THR using a modified version of the search strategy used for a recent review [8]. The search strategies used are presented in the appendix. Appendix [see Additional file 1] The following databases were searched to identify relevant published literature: Cochrane database of systematic reviews (CDSR), Database of abstracts of reviews of effectiveness (DARE), Cochrane Controlled Trials Register, MEDLINE and PREMEDLINE, EMBASE, HealthSTAR, CINAHL, NHS Economic Evaluation Database (EED), and Allied or Alternative Medicine (AMED). Relevant audit databases and the World-Wide Web were also searched. Unpublished data sources were sought by contacting experts in this field and industries with an interest in this area of orthopaedics. Studies from 1990 to 2001 were searched for.

\section{Inclusion and exclusion criteria}

All identified abstracts were assessed for subject relevance independently by two reviewers. Full papers were then obtained and formally assessed for inclusion. It was agreed at the outset of the review that the search strategy would not be limited by language. It was agreed that nonEnglish studies would be identified, but due to time and resource limitations would not be translated and assessed for their relevance to the review. No restrictions on the type of patient were imposed. Comprehensive systematic reviews of THR was carried out in Health Technology Assessment in 1998. These reviews were updated by the National Institute of Clinical Excellence (NICE) in 2000. Therefore, in this review a search for systematic reviews and RCTs published subsequent to the completion of the systematic reviews was carried out. Table 1 describes the inclusion and exclusion criteria applied for each of the treatments considered here.

Table I: Inclusion and exclusion criteria

\begin{tabular}{ll}
\hline Treatment & Inclusion/Exclusion Criteria \\
\hline Metal on metal hip resurfacing & $\begin{array}{l}\text { A minimum of two years follow-up was applied; Studies not reporting the specified outcomes (ref. table 2) } \\
\text { such as laboratory only studies were excluded. }\end{array}$ \\
Observational data of people receiving WW with a follow-up of greater than five years were included \\
Total hip replacement & $\begin{array}{l}\text { RCTs or systematic reviews of RCTs with a minimum of five years follow-up of different methods of THR } \\
\text { and systematic reviews of such trials }\end{array}$ \\
\end{tabular}


Table 2: Outcomes sought from all included studies

\begin{tabular}{ll}
\hline Timescale & Outcomes \\
\hline Short term & Duration of operation \\
& Serious complications (e.g. nerve palsy, haematoma dislocation, infection, re-operation within 6 months \\
& Time in hospital \\
& Time to return to "normal activities" prior to operation \\
& Revision rate \\
Long term & Time to revision surgery \\
& Functional result \\
& Percentage of patients pain free \\
& Quality of life (any recognised generic or condition specific measure e.g. SF-36) \\
& Mortality \\
\hline
\end{tabular}

Table 3: The number of studies identified for different treatments

Number of studies

\begin{tabular}{lll}
\hline Assessment Item & Yes $\quad$ No Unable to judge Not applicable
\end{tabular}

Clarity of study question and definition of outcome

Is the purpose of the study clearly stated?

Is the definition of prosthesis failure clear?

Is there a clear definition of primary outcome(s)?

Are standardised outcome measures used?

Are the outcome measures used appropriate for the purpose of the study?

Description of prosthesis and method of fixation

Is the prosthesis design adequately described?

Is the method of fixation adequately described?

Description of study sample

Is the method of selection of the sample adequately described?

Are the study exclusion and inclusion criteria stated?

Is the baseline sample clearly described in terms of basic characteristics

(age, sex etc)?

Is the study sample sufficiently homogenous in terms of disease/diagnosis?

Is the study sample sufficiently homogenous in terms of co-morbidity?

Control of bias in study design

Is the method of randomisation adequate?

Is the method of masking the patient to the intervention allocated stated?

Were outcome assessors blind to intervention allocation?

Are baseline values for groups compared?

Has the study adequately controlled for confounding factors?

Duration and completeness of follow-up

Are intervals between surgery and follow-up assessment clearly stated?

Are reasons for loss of patients at follow-up stated?

Are those lost to follow-up compared to the rest of the sample?

Is there an appropriate length of follow-up?

Is the length of follow-up at least 5 years?

Statistical and analytical considerations

Has the study sample size been justified?

Are the data clearly presented?

Was the data analyst masked to interventions?

Has type of statistical test and actual probability value been stated?

Are statistical tests appropriate to study?

Is the sample on which failures are assessed adequate?

Are conclusions justified by evidence?

\begin{tabular}{|c|c|c|c|}
\hline 8 & I & I & - \\
\hline 7 & 2 & - & I \\
\hline 7 & 3 & - & - \\
\hline 9 & - & 1 & - \\
\hline 9 & I & - & - \\
\hline 7 & 2 & - & I \\
\hline 7 & 2 & - & I \\
\hline 2 & 7 & I & - \\
\hline 2 & 7 & I & - \\
\hline 6 & 3 & I & - \\
\hline 5 & I & 4 & - \\
\hline 2 & - & 8 & - \\
\hline - & - & I & 9 \\
\hline - & 2 & I & 7 \\
\hline - & I & 3 & 6 \\
\hline - & I & I & 8 \\
\hline I & 7 & 2 & - \\
\hline 8 & 2 & - & - \\
\hline 2 & 2 & 2 & 4 \\
\hline I & 2 & 3 & 4 \\
\hline 8 & 2 & - & - \\
\hline 3 & 7 & - & - \\
\hline - & 9 & I & - \\
\hline 8 & 2 & - & - \\
\hline - & 5 & 3 & 2 \\
\hline 2 & I & I & 6 \\
\hline 2 & - & 2 & 6 \\
\hline - & 2 & 7 & I \\
\hline 5 & I & 3 & I \\
\hline
\end{tabular}




\section{Data abstraction and quality assessment}

Two reviewers independently abstracted data and quality assessed the included studies. Where a difference in opinion occurred, an arbiter was consulted. A data abstraction form was developed to record details of trial methods, participants, interventions, patient's characteristics and pre-specified outcomes (See Table 2). The quality assessment form was based on a checklist developed by Morris, 1988 [2] to assess the quality of studies appearing in orthopaedic research journals.

\section{Results}

The initial search identified 352 potentially relevant MoM studies, 699 potentially relevant THR studies and 177 potentially relevant watchful studies. After reviewing titles and abstracts and applying the inclusion and exclusion criteria, data were abstracted from four published MoM studies [9-12], four published THR studies [2,8,13,14] and one watchful waiting study [15-17]. Four unpublished studies were also included [18-21]. These were obtained from companies that manufacture alternative MoM devices and also through personal communication with the Robert Jones and Agnes Hunt Orthopaedic and District Hospital.))No comparative studies were found.

\section{Quality of studies}

The majority of studies rated poorly in terms of description of study sample, control of bias, and statistical and analytical considerations. Most studies rated favourably in terms of clarity of the study question and definition of outcome, although less favourably with respect to the description of the intervention. The duration and completeness of follow-up was of variable quality, in terms of the interval between surgery and follow-up being clearly stated and the consideration of patients lost to follow-up. Of the three systematic reviews included, two were of high quality $[2,13]$, although there were some limitations on the comprehensiveness of the literature searches. The other systematic review was of lower quality with poor reporting of the methodology [8]. A summary of the quality assessment of the remaining ten included studies is presented in Table 3.

\section{Relative effectiveness of metal on metal hip resurfacing arthroplasty}

Metal on metal hip resurfacing arthroplasty included studies

The MoM studies included in the review were four published studies, three unpublished reports from the manufactures of MoM prostheses, and one unpublished report. (Refer to table 4) The length of follow-up was less than five years for all the studies and ranging from 8.3 months [10] to 48 months [20]. The majority of the studies were small, (4424 [20] to four patients [11]). There was wide variation of patients' pre-operative diagnoses.
Metal on metal hip resurfacing arthroplasty study outcomes

Only one study reported details on the duration of the operation [11]. The mean operation time was reported as 247 minutes (range 180 to 370 minutes). McMinn et al, 1996 [10], reported that all patients were mobilised on the first post-operative day and at 12 days post-operation all patients had partial weight bearing of $25 \mathrm{~kg}$ on the surgically treated leg, with this weight being increased after 12 weeks. Patients in one study [12] spent a median of 21 days in hospital. All except one of the MoM studies reported the revision rates to THR. They ranged from $0 \%$ to $14.3 \%$. Two groups of patients in the McMinn et al, 1996 [17] study were reported to have no revision to THR. Details on patients who were pain free were reported in one published study [17]. In this study $91 \%(60 / 66$ patients) were pain free after a mean follow-up of 50.2 months (range 44 to 54 months). One of the manufacturers of MoM prostheses reported 71.1\% (69/97 patients) to be pain free after a mean follow-up of 16.9 months [18].

The studies reported few complications. In one study [11] $10.5 \%$ (2/19 patients) were reported to have complications, one a femoral nerve palsy and one a haematoma. McMinn et al, 1996 [10] reported out of 235 patients, three patients had infections and one patient had sciatic nerve palsy. The only complication reported by Wagner et al, 1996 [12] (a study of 35 patients), was one patient with a femoral neck fracture, which was due to a traffic accident. The Oswestry Outcome Centre [20] reported the majority of revision surgery was due to fractures (56\%), followed by loosening (19\%), infection (11\%), avascular necrosis (11\%) and dislocation (3\%). One manufacturer reported $6.4 \%$ (7/110 patients) to have complications [18]. Another manufacturer reported 3\% (3/100 patients) to have complications [19]. The most common type of complication in these two studies was loosening.

\section{Alternative treatments to MoM}

Only one watchful waiting study was included in this review. (Refer to table 5) The results of the study were reported in two papers, one with results up to three years [16] and the other up to eight years [17]. All the patients included in the study suffered from osteoarthritis of the hip. The study reported that the THR surgery performed increased from 9 patients (32\%) at 3 years, to 14 patients (48\%) at eight years. The number of patients using walking aids also increased from 8 patients (29\%) at three years, to 12 patients (41\%) at eight years. Patients' level of pain showed a slight increase from three to eight years.

Three systematic reviews provided the majority of information on THR for this review $[2,8,13]$. One of these reviews [2] included 11 RCTs (mean sample 168 patients), 18 comparative observational studies including 
Table 4: Metal-on-metal studies included in review.

\begin{tabular}{|c|c|c|c|c|c|}
\hline Study (Study design) Funding source & Prostheses & $\begin{array}{l}\text { Mean } \\
\text { duration of } \\
\text { follow up } \\
\text { (range) }\end{array}$ & $\begin{array}{l}\text { Mean } \\
\text { patient age } \\
\text { (range) }\end{array}$ & $\begin{array}{l}\text { Revision Rate (unless } \\
\text { otherwise stated) }\end{array}$ & $\begin{array}{l}\text { Hip Score Pre- } \\
\text { operation/Post- } \\
\text { operation }\end{array}$ \\
\hline $\begin{array}{l}\text { Amstutz (2000) [9] Specialist orthopedic } \\
\text { hospital, USA. (Observational) Not } \\
\text { reported }\end{array}$ & $\begin{array}{l}\text { Cemented, modified } \\
\text { McMinn acetabular ( } 7 \\
\text { Hips) } \\
\text { Conserve Plus ( } 29 \\
\text { Hips) }\end{array}$ & $\begin{array}{l}22 \text { months } \\
\text { (NR) }\end{array}$ & $\begin{array}{l}40 \text { years } \\
(N R)\end{array}$ & NR & NR \\
\hline \multirow[t]{4}{*}{$\begin{array}{l}\text { McMinn (1996) [10] } 3 \text { Birmingham } \\
\text { Hospitals, UK. (Observational) Not } \\
\text { reported }\end{array}$} & $\begin{array}{l}\text { Uncemented, } \\
\text { Uncoated (70 Hips) }\end{array}$ & $\begin{array}{l}50.2 \text { months } \\
(44-54)^{\mathrm{a}}\end{array}$ & $\begin{array}{l}48.7 \text { years } \\
(N R)\end{array}$ & $\begin{array}{l}8 / 66 \text { patients }=12.1 \% \\
60 / 66=90.9 \% \\
\text { patients pain free }\end{array}$ & $\begin{array}{l}\text { pain } 3 . I^{b} / 5.3 \\
\text { mobility } 3 . I^{b} / 5.3 \\
\text { walking } 3.1^{b} / 5.3\end{array}$ \\
\hline & $\begin{array}{l}\text { Uncemented, } \\
\text { Hydroxyapetite } \\
\text { coating ( } 6 \text { Hips) }\end{array}$ & $\begin{array}{l}40.2 \text { months } \\
(38-42)^{\mathrm{a}}\end{array}$ & & $0 / 6$ patients $=0 \%$ & $\begin{array}{l}\text { pain } 3.0^{\mathrm{b}} / 5.5 \\
\text { mobility } 3.1^{\mathrm{b}} / 6.0 \\
\text { walking } 2.7^{\mathrm{b}} / 5.7\end{array}$ \\
\hline & $\begin{array}{l}\text { Cemented acetabular } \\
\text { ( } 43 \text { Hips) }\end{array}$ & $\begin{array}{l}33.2 \text { months } \\
(23-38)^{\mathrm{a}}\end{array}$ & & $4 / 39$ patients $=10.3 \%$ & $\begin{array}{l}\text { pain } 2.9 \mathrm{~b} / 5.4 \\
\text { mobility } 3.0^{\mathrm{b}} / 5.4 \\
\text { walking } 3.2^{\mathrm{b}} / 5.4\end{array}$ \\
\hline & $\begin{array}{l}\text { Cemented acetabular, } \\
\text { Hydroxyapetite } \\
\text { coating (I } 16 \text { Hips) }\end{array}$ & $\begin{array}{l}8.3 \text { months } \\
(1-19)^{\mathrm{a}}\end{array}$ & & $0 / 109$ patients $=0 \%$ & $\begin{array}{l}\text { pain } 3.0^{\mathrm{b}} / 5.7 \\
\text { mobility } 3.2^{\mathrm{b}} / 5.7 \\
\text { walking } 3.2^{\mathrm{b}} / 5.7\end{array}$ \\
\hline $\begin{array}{l}\text { Schmalzried (1996) [I I] Specialist } \\
\text { orthopedic hospital, USA. } \\
\text { (Observational) Not reported }\end{array}$ & $\begin{array}{l}\text { Cementless Wagner } \\
\text { (4 Hips) } \\
\text { Cemented McMinn } \\
\text { ( } 7 \text { Hips) }\end{array}$ & $\begin{array}{l}16 \text { months } \\
(10-25)\end{array}$ & $\begin{array}{l}42 \text { years } \\
(22-64)^{\mathrm{a}}\end{array}$ & $1 / 19$ patients $=5.3 \%$ & $\begin{array}{l}\text { pain } 4 c / 9 \\
\text { walking } 6 c / 9 \\
\text { function } 6 c / 9 \\
\text { activity } 4 c d / 7\end{array}$ \\
\hline $\begin{array}{l}\text { Wagner (I996) [1 2] Specialist orthopedic } \\
\text { hospital, Germany. (Observational) Not } \\
\text { reported }\end{array}$ & $\begin{array}{l}2 \text { Ti pins on cupshell } \\
\text { (1 } 2 \text { Hips) } \\
\text { Press fit version ( } 23 \\
\text { Hips) }\end{array}$ & $\begin{array}{l}20 \text { months } \\
(6-54)\end{array}$ & $\begin{array}{l}36 \text { years } \\
(15-64)^{a}\end{array}$ & $5 / 35$ patients $=14.3 \%$ & $\begin{array}{l}32(5-51) \text { e } \\
d / 94(72-100)^{\text {ed }}\end{array}$ \\
\hline $\begin{array}{l}\text { Corin Group Ltd, 200I [I8] } 4 \text { UK } \\
\text { Hospitals, I UK clinic, } 3 \text { surgeons } \\
\text { (Industry submission) Corin Group Ltd }\end{array}$ & Cormet 2000 & 21.36 months $^{f}$ & $\begin{array}{l}50.8 \text { years } \\
(26-69)^{f}\end{array}$ & $\begin{array}{l}\text { Revision Rate CIC } \\
69 / 97=71.1 \% \mathrm{f} \\
\text { Patients pain free }\end{array}$ & NR \\
\hline $\begin{array}{l}\text { Midland Medical Technologies Ltd, 200I } \\
\text { [19] Hospitals in Birmingham } \\
\text { Southampton Liverpool and Belgium } \\
\text { (Industry submission) Midland Medical } \\
\text { Technologies Ltd }\end{array}$ & $\begin{array}{l}\text { Birmingham Hip } \\
\text { Resurfacing (I76I } \\
\text { Patients) }\end{array}$ & NR & $\begin{array}{l}49.2 \text { years } \\
(15-86)\end{array}$ & $8 / 1382$ hips $=0.6 \%$ & NR \\
\hline $\begin{array}{l}\text { Wright Cremascoli Ortho Ltd, 200I [2I] } \\
\text { (Industry submission) Wright Cremascoli }\end{array}$ & $\begin{array}{l}\text { Conserve Plus ( } 100 \\
\text { Hips) }\end{array}$ & NR (24-5I.6) & NR & $3 / 100$ hips $=3 \%$ & NR \\
\hline $\begin{array}{l}\text { Oswestry Outcome Centre Database } \\
\text { [20] Oswestry Outcome Centre } \\
\text { (Unpublished observational data) } \\
\text { Oswestry Outcome Centre }\end{array}$ & $\begin{array}{l}\text { McMinn (I } 378 \text { Hips) } \\
\text { All consultants ( } 4424 \\
\text { Hips) }\end{array}$ & $\begin{array}{l}0-4 \text { years } \\
0-4 \text { years }\end{array}$ & $\begin{array}{l}53.1 \text { (NR) } \\
49.2 \text { (NR) }\end{array}$ & $\begin{array}{l}7 / 1378=0.5 \% \\
34 / 4424=0.77 \%\end{array}$ & $\begin{array}{l}66.2 \mathrm{e} / 98.1 \mathrm{e} \\
61.3 \mathrm{e} / 95.9 \mathrm{e}\end{array}$ \\
\hline $\begin{array}{l}\text { a Median (range) } \\
\text { b Charnley hip score } \\
\text { c UCLA hip score } \\
\text { d Results of groups reported together } \\
\text { e Harris hip score } \\
\text { f Data from } 97 \text { patients (I } 10 \text { hips); } \\
\text { CIC - Data marked as "Commercial in co } \\
\text { NR - Not Reported }\end{array}$ & 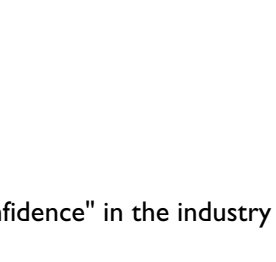 & port & & & \\
\hline
\end{tabular}

two very large studies based on Scandinavian registry data [22], and 159 observational studies. The second systematic review [13] included 17 RCTs, 61 comparative studies and 145 observational studies. The third review [8] included the two systematic reviews mentioned above in addition to four RCTs, ten prospective comparative observational studies and Swedish Registry data [22]. One addi- tional recent RCT [14] not included in the earlier systematic reviews was found from the search in this review. (Refer to table 6) The review by Fitzpatrick et al 1998 [2], reported an adjusted revision rate per 100 person years at risk of $0.37(+/-0.02)$. Faulkner et al, 1998 [13] reported that cemented designs show good survival at ten to 15 years. The review by NICE, 2001 [8] reported 
Table 5: Watchful waiting studies

\begin{tabular}{|c|c|c|c|c|c|}
\hline $\begin{array}{l}\text { Study (Study Design) Funding } \\
\text { source }\end{array}$ & $\begin{array}{l}\text { Patient } \\
\text { Characteristics }\end{array}$ & $\begin{array}{l}\text { Patients pain level } \\
\text { at baseline }\end{array}$ & $\begin{array}{l}\text { Patients pain level } \\
\text { at follow-up }\end{array}$ & Use of walking aids & Notes \\
\hline $\begin{array}{l}\text { Dieppe (1997) [I6] Single } \\
\text { orthopedic unit (UK) Follow up: } \\
\text { Mean (range) } 37.6 \text { months ( } 31- \\
4 I) \text { (Observational study } \\
\text { Arthritis and Rheumatism } \\
\text { Council }\end{array}$ & $\begin{array}{l}N=84 \text { patients } \\
\text { Mean age (SD): } 50 \\
(12.1)\end{array}$ & $\begin{array}{l}\text { None }=7 \% \\
\text { Mild }=48 \% \\
\text { Moderate }=31 \% \\
\text { Severe }=10 \%\end{array}$ & $\begin{array}{l}\text { None }=4 \% \\
\text { Mild }=50 \% \\
\text { Moderate }=32 \% \\
\text { Severe }=14 \%\end{array}$ & $\begin{array}{l}9 \text { patients }(32 \%) \text { at } \\
\text { baseline } \\
8 \text { patients ( } 29 \%) \text { at } 3 \\
\text { year follow up }\end{array}$ & $\begin{array}{l}\text { All patients had } \\
\text { symptomatic limb } \\
\text { joint osteoarthritis. } \\
\text { Surgery performed in } \\
9 \text { patients }(32 \%)\end{array}$ \\
\hline $\begin{array}{l}\text { Dieppe (2000) [17] Single } \\
\text { orthopedic unit (UK) Follow up: } \\
\text { Mean (range) NR (36-96) } \\
\text { (Observational study) Arthritis } \\
\text { and Rheumatism Council }\end{array}$ & $\begin{array}{l}N=29 \text { patients } \\
\text { Mean age (SD): } 50 \\
(12.1)\end{array}$ & $\begin{array}{l}\text { None }=7 \% \\
\text { Mild }=48 \% \\
\text { Moderate = } 31 \% \\
\text { Severe }=10 \%\end{array}$ & $\begin{array}{l}\text { None }=3 \% \\
\text { Mild = 34\% } \\
\text { Moderate }=48 \% \\
\text { Severe }=14 \%\end{array}$ & $\begin{array}{l}\text { I } 2 \text { patients ( } 41 \%) \text { at } 8 \\
\text { year follow up }\end{array}$ & $\begin{array}{l}\text { All patients had } \\
\text { symptomatic limb } \\
\text { joint osteoarthritis. } \\
\text { Surgery performed in } \\
\text { I } 4 \text { patients }(48 \%)\end{array}$ \\
\hline
\end{tabular}

Note: The studies above involve the same population, but have different length of follow up. NR: Not Reported.

Table 6: Total hip replacement RCTs of 5 years or more duration not included in the systematic reviews $[2,8,13]$.

\begin{tabular}{|c|c|c|c|c|c|}
\hline Study (Study Design) & Prostheses & $\begin{array}{l}\text { Patient } \\
\text { Characteristics }\end{array}$ & $\begin{array}{l}\text { Mean duration of } \\
\text { follow up (range) }\end{array}$ & Revision Rate ${ }^{b c}$ & Hip score post-opd \\
\hline $\begin{array}{l}\text { Sharp (2000) [14] } 2 \text { Hospitals } \\
\text { (UK)a (Observational study) No } \\
\text { funding received }\end{array}$ & $\begin{array}{l}\text { C-Fit uncemented } \\
\text { with hydroxyapatite } \\
\text { porous coating of } \\
\text { components }\end{array}$ & $\begin{array}{l}\mathrm{N}=9 \mathrm{I} \text { in total for } \\
\text { both groups } \\
\text { Mean age: }<66 \text { years }\end{array}$ & $\begin{array}{l}5.2 \text { years (I month- } \\
8 \mathrm{yrs})\end{array}$ & $25 / 91=27.5 \%$ & $\begin{array}{l}\text { score/patients } \\
12-20 / 35 \\
21-30 / 13 \\
3 I-40 / 12 \\
4 I-50 / 1 \\
50-60 / 2\end{array}$ \\
\hline
\end{tabular}

a: I center randomised, I center not randomised

b: Revision rate at latest follow-up point \& crude survival rate based on all patients

c: Results reported by patient number on entry to trial i.e. intention to treat

d: Oxford Hip Score

NR: Not Reported

that a number of prostheses achieved a revision rate of $10 \%$ or less after ten or more years follow-up. The study by Sharp et al, 2000 [14] reported a revision rate of $27.5 \%$ at a mean follow-up of 5.2 years. It was also reported in this study that two out of 91 patients $(2.2 \%)$ had a dislocation within one year post-operation. No evidence on the extent or nature of complications was reported in any of the systematic reviews.

\section{Discussion}

Despite extensive searching for relevant studies, the evidence base for making comparisons between MoM and any of the comparators is limited. Initial searches had already shown a lack of comparative studies and therefore the focus of the literature search was on identifying less methodologically robust studies such as data from case series. Although such searches are problematic due to lack of specific indexing terms, an extensive search strategy was devised to identify as many eligible studies as possible.
The early data pertaining to MoM suggests that MoM has the potential to be an effective technique for the management of hip disease. However, due to the lack of any controlled studies, it is difficult to know how much more or less effective it is compared to any comparators. The data available with which to make comparisons is uncontrolled and the studies identified have, in many cases, considered patient populations that are dissimilar in many ways. Identified studies also did not always use comparable outcomes and had different lengths of follow-up.

The lack of long-term data on MoM makes it difficult to compare with the other comparators. In particular the failure rates for some types of THR prosthesis increase significantly after ten years [2], and it is possible the same could occur with MoM. It is also unclear whether the success rates reported for THR could be replicated in younger or more active populations. Comparisons between MoM and THR studies are difficult as the MoM studies included 
younger patients and had shorter follow-up than the THR studies. The evidence from the systematic reviews of different methods of THR reported that several prostheses had revision rates of ten percent or less at ten years or more $[2,13]$. Revision rates reported in the MoM studies ranged from $0 \%$ to $14 \%$ for up to 5 years follow-up. The only other outcome that could be compared is the percentage of patients who were pain-free at follow-up. This was reported to be $90.9 \%$ at 50.2 months follow-up in one group of patients in one MoM study [10]. The systematic review conducted by Fitzpatrick and colleagues in 1998 report a mean of $84.1 \%$ (range $46-100 \%$ ) of patients pain-free at a follow-up of 11 years [2].

In the MoM and WW studies, most of the patients had a preoperative diagnosis of osteoarthritis and were all of a similar younger age. The watchful waiting study reported $32 \%$ of patients requiring surgery at 3 years and $48 \%$ by eight years follow-up [15-17]. In the MoM studies revision rates ranged from $0 \%$ to $14.3 \%$, after a follow-up of less than five years. During the 8-year follow-up period, people managed with WW had a slight increase in their pain levels, whereas the MoM patients hip scores all improved. $91 \%(60 / 66)$ of MoM patients were pain free after a mean follow-up of 50.2 months in one study [10], and $71 \%$ (69/97) after a mean follow-up of 16.9 months in the only other study that reported this outcome [18]. The very limited evidence available suggests that MoM is more effective in terms of better quality of life (measured by pain scores for WW and hip scores for MoM) than WW over a follow-up of approximately three years.

As the relative effectiveness of MoM is unclear the costeffectiveness of MoM is also uncertain. It is likely the MoM procedure would cost approximately $£ 5,500$ whereas a THR would cost about $£ 4,200$ and the annual cost of WW (including the cost of NSAID (Non steroidal anti-inflammatory drugs) therapy, physiotherapy and treatment of side effects of medications) would be about $£ 640$ [23]. Whether MoM proves to be cost-effective against these alternatives depends upon the rates of revision to THR of MoM and WW, and the rates of revision of THR. The operation rates reported from the one WW study [15-17] and the revision rates of MoM suggest that MoM may provide better outcome at lower cost over a ten-year period. Such information remains at best tentative due to the small number of people to whom the watchful waiting data relate, the short follow-up of the MoM studies, and the uncontrolled nature of the comparison.

\section{Conclusions}

The use of MoM in the UK is still relatively rare. However, there has been increasing interest from younger people with hip disease who are not currently considered eligible for THR and amongst surgeons who strive for better ways to treat the patients whom they see. However, only very limited evidence are currently available on MoM and although the procedure does appear promising the lack of robust comparisons with the other treatment options and of long term data make it virtually impossible to draw robust conclusions about its relative effectiveness. Given the early promise shown by MoM there is a real need for more rigorous research. Such research would be challenging, not least because of ethical considerations, but should attempt some form of prospective, preferably randomised, comparison of MoM with a policy of delayed selective surgery. These studies should preferably be largescale, long-term, and use standard outcome measures, both pre- and post-operatively.

\section{Competing interests}

The author(s) declare that they have no competing interests.

\section{Authors' contributions}

LW carried out the critical appraisal of the included studies and assisted in the writing up. LV coordinated the project and assisted in the writing up. KM developed the methodology for the literature search and assisted in the writing up. AG participated in the design and coordination of the study. $\mathrm{MB}$ assisted in the critical appraisal of the included studies. All authors read and approved the final manuscript.

\section{Additional material}

\section{Additional File 1}

Search strategies. The search strategies used to search electronic databases to identify studies relevant to this review.

Click here for file

[http://www.biomedcentral.com/content/supplementary/14726963-4-39-S1.doc]

\section{Acknowledgements}

This review was commissioned by the HTA Programme on behalf of the National Institute for Clinical Excellence (NICE). The Health Services Research Unit and the Health Economics Research Unit are core funded by the Scottish Executive Health Department. The views expressed are those of the authors and not necessarily those of the funding bodies.

\section{References}

I. Northmore-Ball MD: Young Adults with Arthritic Hips. BMJ 1997, 3 I 5:265-266.

2. Fitzpatrick R, Shortall E, Sculpher M, Murray D, Morris R, Lodge M, Dawson J, Carr A, Britton A, Briggs A: Primary total hip replacement surgery: a systematic review of outcomes and modelling of cost effectiveness associated with different prostheses. Health Technol Assess 1998, 2(20): I-64.

3. Joshi $A B$, Porter ML, Trail IA, Hunt LP: Long term results of Charnley low friction arthroplasty in young patients. J Bone Joint Surg Br 1993, 75(4):616-623. 
4. Department of Health: Hospital In-Patient Data [http:// www.doh.gov.uk/hes/standard data/index.html]. (accessed 10-30200I)

5. National Institute of Clinical Excellence: Appraisal of new and existing technologies: Interim guidance for manufacturers and sponsors. 1999 [http://server2.nice.org.uk/ embcat2.asp?.page=oldsite/appraisals/apr gide.htm]. (accessed 10-30200I)

6. The Royal Academy of Engineering: Joint replacement: once is forever. The Royal Academy of Engineering; 2000.

7. Frankel S, Eachus J, Pearson N, Greenwood R, Chan P, Peters T, Donovan J, Davey Smith G, Dieppe P: Population requirement for primary hip-replacement surgery: a cross-sectional study. Lancet 1999, 353:1304-1309.

8. National Institute of Clinical Excellence: The effectiveness and cost effectiveness of different prostheses for primary total hip replacement. [http://www.nice.org.uk]. (accessed 5-I-200I)

9. Amstutz HC: Arthroplasty options for advanced osteonecrosis. Orthopedics 2000, 23:927-928.

10. McMinn D, Treacy R, Lin K, Pynsent P: Metal on metal surface replacement of the hip. Clinical Orthopaedics and Related Research 1996, 329S:89S-98S.

II. Schmalzried TP, Fowble VA, Ure KJ, Amstutz HC: Metal on metal surface replacement of the hip. Clinical Orthopaedics and Related Research 1996, 329S: I06S-I I 4S.

12. Wagner $M$, Wagner $\mathrm{H}$ : Preliminary results of uncemented metal on metal stemmed and resurfacing hip arthroplasty. Clinical Orthopaedics and Related Research 1996, 329S:78S-88S.

13. Faulkner A, Kennedy LG, Baxter K, Donovan J, Wilkinson M, Bevan G: Effectiveness of hip prostheses in primary total hip replacement: a critical review of evidence and an economica model. Health Technology Assessment 1998, 2(6):

14. Sharp RJ, O'Leary ST, Falworth M, Cole A, Jones J, Marshall RW: Analysis of the results of the C-Fit uncemented total hip arthroplasty in young patients with hydroxyapatite or porous coating of components. Journal of Arthroplasty 2000, I 5:627-634.

15. Cushnaghan J, Dieppe P: Study of $\mathbf{5 0 0}$ patients with limb joint osteoarthritis. Analysis by age, sex, and distribution of symptomatic joint sites. Annals of the Rheumatic Diseases 1991, 50:8.

16. Dieppe P, Cushnaghan J, Shepstone L: The Bristol 'OA500 study': progression of osteoarthritis (OA) over 3 years and the relationship between clinical and radiographic changes at the knee joint. Osteoarthritis and Cartilage 1997, 5:87-97.

17. Dieppe P, Cushnaghan J, Tucker M, Browning S, Shepstone L. The Bristol 'OA500 study': progression and impact of the disease after 8 years. Osteoarthritis and Cartilage 2000, 8:63.

18. Corin Group Ltd: Industry Submission 200 I. In: Systematic review of the effectiveness and cost-effectiveness of metal on metal hip resurfacing arthroplasty for treatment of hip disease. Health Technology Assessment 2002, 6: 15 .

19. Midland Medical Technologies Ltd: Industry Submission 200I. In: Systematic review of the effectiveness and cost-effectiveness of metal on metal hip resurfacing arthroplasty for treatment of hip disease. Health Technology Assessment 2002, 6:15.

20. Oswestry Outcome Centre: Oswestry Outcome Centre, The Robert Jones and Agnes Hunt Orthopaedic and District Hospital NHS Trust. In: Systematic review of the effectiveness and costeffectiveness of metal on metal hip resurfacing arthroplasty for treatment of hip disease. Health Technology Assessment 2002, 6:15.

21. Wright Cremascoli Ortho Ltd: Industry Submission 200I. In: Systematic review of the effectiveness and cost-effectiveness of metal on metal hip resurfacing arthroplasty for treatment of hip disease. Health Technology Assessment 2002, 6:15.

22. Swedish Hip Registry: Prognosis of Total Hip Replacement. 2000 [http://www.jru.orthop.gu.se].

23. Vale L, Wyness L, McCormack K, McKenzie L, Brazzelli M, Stearns SC: Systematic review of the effectiveness and cost-effectiveness of metal on metal hip resurfacing arthroplasty for treatment of hip disease. Health Technology Assessment 2002, 6:15.

\section{Pre-publication history}

The pre-publication history for this paper can be accessed here: http://www.biomedcentral.com/1472-6963/4/39/prepub
Publish with Biomed Central and every scientist can read your work free of charge

"BioMed Central will be the most significant development for disseminating the results of biomedical research in our lifetime. " Sir Paul Nurse, Cancer Research UK

Your research papers will be:

- available free of charge to the entire biomedical community

- peer reviewed and published immediately upon acceptance

- cited in PubMed and archived on PubMed Central

- yours - you keep the copyright
BioMedcentral 